\title{
Removal of the pesticide thiamethoxam from sugarcane juice by magnetic nanomodified activated carbon
}

\author{
Driélle Aparecida de Freitas ${ }^{1}$ Júlia Adorno Barbosa ${ }^{1} \cdot$ Geórgia Labuto $^{2,3} \cdot$ Roberta Cornélio Ferreira Nocelli ${ }^{4}$. \\ Elma Neide Vasconcelos Martins Carrilho ${ }^{1,4}$ (i)
}

Received: 15 September 2021 / Accepted: 29 December 2021 / Published online: 8 January 2022

( $)$ The Author(s), under exclusive licence to Springer-Verlag GmbH Germany, part of Springer Nature 2022

\begin{abstract}
The removal of the neonicotinoid and systemic pesticide thiamethoxam (TMX) from water and sugarcane juice by magnetic nanomodified activated carbon (AC-NP) is proposed. This adsorbent was synthesized and characterized by FTIR, XRD, and SEM, and TMX was quantified by high-performance liquid chromatography coupled to a diode array detector (HPLCDAD). The AC-NP was efficiently synthesized using a co-precipitation method and the impregnation of magnetite (NP) in the activated carbon $(\mathrm{AC})$ was assessed by the crystalline planes found in the AC-NP structure shown in the XRD diffractograms. The AC-NP FTIR analysis also indicated predominant bands of $\mathrm{Fe}-\mathrm{O}$ stretching of the magnetite at $610-570 \mathrm{~cm}^{-1}$. Functional groups in AC and AC-NP were identified by absorption bands at 3550 and $1603 \mathrm{~cm}^{-1}$, characteristic of O-H and $\mathrm{C}=\mathrm{C}$, respectively. The TMX adsorption kinetics in sugarcane juice was the pseudo-second-order type with $r^{2}=0.9999$, indicating a chemical adsorption process. The experimental sorption capacity $\left(S C_{\text {exp }}\right)$ for both TMX (standard) and TMX-I (insecticide) by AC-NP were 13.44 and $42.44 \mathrm{mg} / \mathrm{g}$, respectively. Seven non-linear isotherm models (Langmuir, Freundlich, Dubinin-Radushkevich, Toth, Hill, Sips, and Redlich-Peterson) were fitted to the experimental adsorption data of TMX and TMX-I by AC-NP. Considering the standard error (SE), Freundlich, Langmuir, and Sips were the most appropriate models to describe the TMX adsorption, and Hill's best adjusted to TMX-I experimental data. The chromatographic method was highly satisfactory due to its high selectivity and recovery (91-103\%). The efficiency of AC-NP in the sorption of TMX was confirmed by the excellent values of $S C_{\text {exp }}$ and sorption kinetics.
\end{abstract}

Keywords Adsorption $\cdot$ Magnetic nanoparticles $\cdot$ Water treatment $\cdot$ Insecticide $\cdot$ Isotherm models

\section{Introduction}

Responsible Editor: Tito Roberto Cadaval Jr

Elma Neide Vasconcelos Martins Carrilho

elma.carrilho@gmail.com

1 Laboratory of Polymeric Materials and Biosorbents, Federal University of São Carlos, Araras, SP 13604-900, Brazil

2 Laboratory of Integrated Sciences, Federal University of São Paulo, Diadema, SP 09972-270, Brazil

3 Departamento de Química, Universidade Federal de São Paulo, Diadema, SP 09913-030, Brazil

4 Departamento de Ciências da Natureza, Matemática e Educação, Universidade Federal de São Carlos, Araras, SP 13604-900, Brazil
The cultivation of sugarcane (Saccharum spp.) is considered one of the oldest and most important in human civilization, and due to the edaphoclimatic conditions, Brazil has become the largest producer of sugarcane, followed by India and China. The state of São Paulo alone accounting for almost $55 \%$ of the national production (CONAB 2021). Since the COVID-19 pandemic, Brazil has gained even more prominence in agricultural products (USDA 2020), which further drives the Brazilian agricultural market economically. Its cultivation is mainly reusable, for example, the ethanol used as fuel to move cars (Angelo 2012), or the byproduct of the sugar and alcohol industry, the vinasse, that can be used to fertigate crops (Carrilho et al. 2016). In addition, it allows the use of various industrial and artisanal products, such as the sugarcane juice obtained through the milling of the plant. 
It is a drink widely consumed in local markets and fairs in the countries where this culture is found, such as Brazil, and also the precursor in sugar production. However, due to the wide variety of pesticides and insecticides used in the sector to avoid damage and losses from pests attack, the products captured from sugarcane are not free from contaminants (Antunes-Kenyon and Kennedy 2001).

The insecticide thiamethoxam (3-[(2-chloro-1,3-thiazol5-yl) methyl]-5-methyl-N-nitro-1,3,5-oxadiazinan-4-imine), called TMX in this study, is used in the cultivation of sugarcane to control leafhopper (Mahanarva fimbriolata) (Ravaneli et al. 2006). It is one of the main neonicotinoids in the class and has systemicity as one of its main characteristics (Maienfisch et al. 2001). The TMX presents high toxicity to honeybees and has been forbidden to use in Europe since it was associated with the massive death of bees in the 1990s in Sweden (Brandt et al. 2016). However, in Brazil, despite the death of 500 million bees between 2018 and 2019 , it has been legally and widely used in foliar applications of sugarcane cultivation, and its sales data has not been disclosed due to trade secrets. There are sales estimates for 10 thousand tons of TMX in 2018. As far as we are aware, there are no records of maximum residual limits for TMX in sugarcane juice in legislation and regulations of European, American, or other countries and continents. However, there is a limit established for sugarcane by the European Food Safety Authority $(0.5 \mathrm{mg} / \mathrm{kg})$ and proposed by the US Environmental Protection Agency (0.2 mg/kg) (EFSA 2014; EPA 2020).

Due to the toxic characteristics of TMX (Uğurlu et al. 2015), the use of adsorbents as alternatives for its remediation has stood out. Among these, activated carbon (AC) exhibits characteristics and properties favorable to this interest, such as pore structure, high specific surface area, availability of sorption sites, ease to obtain, and can be produced from biomass waste (El-Sheikh et al. 2007; Foo and Hameed 2010; Gupta et al. 2011; Modesto et al. 2021). However, $\mathrm{AC}$ presents a high interaction with the aqueous medium, which is minimized by magnetizing the adsorbent material with magnetite (Panneerselvam et al. 2011). Activated carbon and nanomodified carbon, in turn, have already been used to remove and quantify substances of interest in complex samples and have shown efficient treatment (Pyrzynska 2013; Rodrigues et al. 2010; Wen 2020; Barbosa et al. 2021). In addition, the derivatives of this inorganic class have shown great alternatives as adsorbent materials for pre-concentration of analytes and applications in analytical separation techniques.

Given the above, this work aims to evaluate the removal of the insecticide TMX from sugarcane juice, an extremely complex matrix, and water by applying a magnetic activated carbon nanocomposite (AC-NP), and determining TMX in these samples by high-performance liquid chromatography, with diode array detection (HPLC-DAD). Magnetization was a strategy to facilitate the separation of the adsorbent from the liquid matrix from which the contaminant is to be removed (Labuto et al. 2018; Cardona et al. 2019). The novelty of this work is the removal of the pesticide most used for sugarcane cultivation from the juice used for the production of sugar.

\section{Material and methods}

\section{Reagents and analytical standards}

High purity thiamethoxam (TMX) standard (Sigma-Aldrich, $98 \%$ ) and the commercially available insecticide $250 \mathrm{WG}{ }^{\circledR}$ (TMX-I) (Syngenta, 25\% w/w) were used in the adsorption essays. HPLC grade acetonitrile (ACN) (Honeywell, USA) was used in the composition of the mobile phase and TMX solution preparation. Powdered activated carbon (AC), ammonium hydroxide, hydrochloric acid, iron (II) sulfate, and hydrated iron (III) chloride (Labsynth, São Paulo, Brazil) were used in the synthesis of the composite.

Ultrapure water from a Direct-Q® 3 System (Merck, Millipore ${ }^{\circledR}$, Germany), under $25^{\circ} \mathrm{C}$ and $18.2 \mathrm{M} \Omega / \mathrm{cm}$ resistivity, was used to prepare all solutions. Mesoporous activated carbon, $\mathrm{FeCl}_{3} \cdot 6 \mathrm{H}_{2} \mathrm{O}, \mathrm{FeSO}_{4} \cdot 7 \mathrm{H}_{2} \mathrm{O}, \mathrm{HCl}$, and $\mathrm{NH}_{4} \mathrm{OH}$ (Labsynth, São Paulo, Brazil) were used to synthesize the magnetic materials.

All reagents and samples were filtered $(0.45 \mu \mathrm{m}$ Millex®) before the HPLC analysis. The composition of the mobile phase (MP) was 30:70 (v/v) acetonitrile:ultrapure water. The MP was filtered in $0.45 \mu \mathrm{m}$ PTFE membrane (regenerated cellulose, Unifil, São Paulo, Brazil) supported on a porous plate glass funnel (1.0-1.6 $\mu \mathrm{m})$, coupled to a vacuum pump (Millipore ${ }^{\circledR}$, model WP6111560, Billerica, USA). After filtration, the MP degassing was performed by sonication in an ultrasonic bath (Unique, USC 2800 model, São Paulo, Brazil) for $30 \mathrm{~min}$ before the chromatographic analysis.

TMX stock solution (1000 mg/L in ACN 60\% v/v) was used to prepare the work solutions and analytical curves by appropriate dilutions of high purity (99\%) TMX standard and TMX-I commercial insecticide. The analytical curves were acquired with $10,15,20,25$, and $30 \mathrm{mg} / \mathrm{L}$ TMX or TMX-I solutions. All solutions were stored in amber bottles and kept under refrigeration at $5{ }^{\circ} \mathrm{C}$.

\section{Chromatographic operating conditions}

TMX determination was conducted by high-performance liquid chromatography, using a UHPLC Dionex Ultimate 3000 (Thermo Fisher Scientific, USA), equipped with an LPG-3400SD pump and a DAD detector operating at $210 \mathrm{~nm}$. A C18 $(5 \mu \mathrm{m}, 3.5 \times 150 \mathrm{~mm})$ column (Waters, 
USA) and acetonitrile (Sigma-Aldrich, USA) mobile phase (acetonitrile:water 30:70) at $0.7 \mathrm{~mL} / \mathrm{min}$ flow rate was used for TMX separation. The temperature of the column compartment was around $30^{\circ} \mathrm{C}$, a sample injection volume of 20 $\mu \mathrm{L}$, and a 10-min analysis time (Jiménez-López et al. 2020; Suganthi et al. 2018).

\section{Synthesis of nanomodified activated carbon (AC-NP)}

The nanomodified activated carbon (AC-NP) synthesis was performed using the coprecipitation method (Barbosa et al. 2021; Panneerselvam et al. 2011). In this procedure, the salts $\mathrm{FeSO}_{4} \cdot 7 \mathrm{H}_{2} \mathrm{O}$ and $\mathrm{FeCl}_{3} \cdot 6 \mathrm{H}_{2} \mathrm{O}$ were mixed and dissolved in an acidic medium $(1.0 \mathrm{~mol} / \mathrm{L} \mathrm{HCl})$ under stirring. Following, $200 \mathrm{~mL}$ of $0.7 \mathrm{~mol} / \mathrm{L} \mathrm{NH}_{4} \mathrm{OH}$ solution was slowly dropped into the iron salt solution to finalize the synthesis of the magnetic nanoparticles (NP). The produced suspension of magnetic nanoparticles (NP), $\mathrm{Fe}_{3} \mathrm{O}_{4}$, was either dried to obtain the powdered NP or used to synthesize AC-NP. For this, AC was slowly added to the NP-containing suspension in a 5:1 ratio (AC:NP), at $80{ }^{\circ} \mathrm{C}$, under constant stirring for $30 \mathrm{~min}$ (IKA®, model C-MAG HS 7, Germany). The synthesized materials (NP and AC-NP) were separated from the mixture by employing a neodymium magnet and freeze-dried. For the synthesis of NP and AC-NP are involved, respectively, Reactions 1 and 2.

$$
\begin{aligned}
& \mathrm{FeSO}_{4} \cdot 7 \mathrm{H}_{2} \mathrm{O}_{(\mathrm{s})}+2 \mathrm{FeCl}_{3} \cdot 6 \mathrm{H}_{2} \mathrm{O}_{(\mathrm{s})} \\
& \quad+8 \mathrm{NH}_{4} \mathrm{OH}_{(\mathrm{l})} \rightarrow \mathbf{F e}_{3} \mathbf{O}_{4(\mathrm{~s})}+6 \mathrm{NH}_{4} \mathrm{Cl}_{(\mathrm{aq})} \\
& +\left(\mathrm{NH}_{4}\right)_{2} \mathrm{SO}_{4(\mathrm{aq})}+17 \mathrm{H}_{2} \mathrm{O}_{(\mathrm{l})} \\
& \mathrm{Fe}_{3} \mathrm{O}_{4(\mathrm{~s})}+\mathrm{AC}_{(\mathrm{s})} \rightarrow \mathbf{A C}-\mathbf{F e}_{3} \mathbf{O}_{4(\mathrm{~s})}
\end{aligned}
$$

\section{Characterization of nanomodified activated carbon (AC-NP)}

Fourier transform infrared spectroscopy (FTIR), X-ray diffractometry (XRD), and scanning electron microscopy (SEM) were used in the characterization studies of the magnetic nanocomposite.

A Fourier transform infrared spectrometer (FTIR, Bruker Vertex Model, USA) was used to identify functional groups responsible for the adsorption process by the adsorbent. Approximately $1 \mathrm{~g}$ of $\mathrm{AC}-\mathrm{NP}$ and $100 \mathrm{mg}$ of $\mathrm{KBr}$ were pressed into pellets. The analysis was performed with 16 scanners in the range of 4000 to $400 \mathrm{~cm}^{-1}$ and resolution of $4 \mathrm{~cm}^{-1}$ and 16 scans per sample. The X-ray analysis was performed with a diffractometer (Rigaku Mini Flex 600, Japan) operated with a CuKa tube $(\lambda=15,406 \AA)$ at $40 \mathrm{kV}$ voltage and $30 \mathrm{~mA}$ current. For this, approximately $1 \mathrm{~g}$ of AC-NP was used, and data were acquired in the 2 to $90^{\circ}$ range at $0.02^{\circ}$ per second rate and analyzed based on the standard JCPDS (Joint Committee on Powder Diffraction Standards) sheet of magnetite.

Scanning electron microscopy (SEM) images were obtained with a ZEISS LEO 440 (Cambridge, England) microscopy and an OXFORD detector (model 7060), operating with an electron beam, under $10 \mathrm{kV}, 2.82 \mathrm{~A}$, and 200 pA I probe. The samples were carbon-coated in a BAL-TEC MED 020 coating system metallizer (BAL-TEC, Liechtenstein) and stored in a desiccator until analysis.

\section{Adsorption kinetics}

The $\mathrm{pH}$ of sugarcane juice was initially measured to verify the need to adjust it to the favorable adsorption $\mathrm{pH}$, according to the $\mathrm{pH}_{\mathrm{PZC}}$ ( $\mathrm{pH}$ at point of zero charge) of AC-NP, previously determined as 6.4 (Barbosa et al. 2021). The sugarcane juice $\mathrm{pH}$ was 5.3, which is below the $\mathrm{pH}_{\mathrm{PZC}}$. At this $\mathrm{pH}$ value, the surface charge of AC-NP is predominantly positive and favors the sorption of TMX. Therefore, we prioritized using $\mathrm{pH}=5.3$ to perform the sorption of TMX by AC-NP in sugarcane juice. The $\mathrm{pH}$ measurements were made before and after sorption, using a calibrated benchtop pH meter (Bel Engineering, PHS 3 model, Monza, Italy) operating in the $0.00-14.00( \pm 0.01) \mathrm{pH}$ range at $25^{\circ} \mathrm{C}$.

Sugarcane juice was fortified from a $500 \mathrm{mg} / \mathrm{L}$ TMX stock solution to a final $10 \mathrm{mg} / \mathrm{L}$ TMX concentration. In Falcon tubes, $40 \mathrm{~mL}$ of $10 \mathrm{mg} / \mathrm{L}$ TMX solution aliquots were mixed with $100 \mathrm{mg}$ of AC-NP. The mixtures were incubated under constant stirring $(120 \mathrm{rpm})$ at $24{ }^{\circ} \mathrm{C}$, increasing contact times of 5, 10, 30, 60, and $120 \mathrm{~min}$. Aliquots of $2 \mathrm{~mL}$ of each supernatant were diluted in the mobile phase $(1: 1)$, filtered (Millex ${ }^{\circledR} 0.45 \mu \mathrm{m}$ ) into the injected sample vials for TMX quantification by high-performance liquid chromatography, coupled to a diode array detector (HPLC-DAD), under the chromatographic operating conditions previously described.

\section{Nanomodified activated carbon sorption capacity $\left(S C_{\text {exp }}\right)$}

Sugarcane juice samples were spiked with TMX to achieve final concentrations of $10,20,40,60,80,100,150$, and $200 \mathrm{mg} / \mathrm{L}$, performed in triplicates. Then, into 15-mL Falcon tubes containing $50 \mathrm{mg}$ of $\mathrm{AC}-\mathrm{NP}$, a $10 \mathrm{~mL}$ aliquot of each solution was added and the mixtures were kept under constant agitation for $15 \mathrm{~min}$ on a shaker at $120 \mathrm{rpm}$ at $25^{\circ} \mathrm{C}$. The same procedure was applied to determine the sorption capacity for the insecticide (TMX-I) in sugarcane juice by AC-NP. Solutions containing 15, 35, 70, 120, 300, 730, 1300 , and $2500 \mathrm{mg} / \mathrm{L}$ TMX-I in sugarcane juice were used. 
Aliquots of $2 \mathrm{~mL}$ of the supernatants (TMX or TMX-I) were diluted in the mobile phase (1:1), filtered in Millex ${ }^{\circledR}$ filters $(0.45 \mu \mathrm{m})$ coupled to polycarbonate syringe, directly into the vials using manual pressure, for TMX quantification by HPLC. The analysis was performed in triplicate under the chromatographic operating conditions previously described. Seven non-linear isotherm models were fitted to experimental data of TMX and TMX-I adsorption by AC-NP, five twoparameter models Langmuir, Freundlich, Dubinin-Radushkevich (DR), Toth, and Hill, and two three-parameter models Sips and Redlich-Peterson (RP) (Al-Ghouti and Da'ana 2020).

\section{Results and discussion}

\section{Characterization of nanomodified activated carbon (AC-NP)}

In our previous work (Barbosa et al. 2021), we demonstrated that AC-NP was efficiently synthesized, characterized by SEM, EDS, XRD, and FTIR, and used for organic acid adsorption in an aqueous medium. The authors discussed and elucidated the surface and active sites of this adsorbent for aconitic and citric acids. In the present work, some relevant SEM, XRD, and FTIR results on the sorption of the pesticide TMX and TMX-I in sugarcane juice and water matrices are discussed.

Figure $1 \mathrm{~A}$ and $\mathrm{B}$ exhibit SEM images at $2 \mathrm{~K} \times$ and $5 \mathrm{~K} \times$, respectively, indicating the efficiency of AC-NP synthesis. It is possible to observe the apparent porosity and small size of the nanoparticle impregnated in the AC. The proximal length of the particle in the higher approximation $(5 \mathrm{~K} \times)$ was $55.36 \mu \mathrm{m}$, calculated by using the ImageJ software.

To verify the presence of magnetite in the synthesized AC-NP, X-ray diffraction analysis was performed for the precursors ( $\mathrm{AC}$ and $\mathrm{NP}$ ), the nanocomposite, and the nanocomposite after adsorption of TMX and TMX-I in water and sugarcane juice. Reference values (standard plug JCPDF 88-0315) of $2 \theta$ for all peaks corresponding to $\mathrm{Fe}_{3} \mathrm{O}_{4}$ and the results for $\mathrm{AC}$ and $\mathrm{AC}-\mathrm{NP}$ prior and after sorption are presented in Table 1.

According to the XRD analysis, the magnetite nanoparticles showed crystalline structure, as expected, as seen in the diffractograms exhibited in Fig. 2. The crystalline structure of AC-NP shows the peaks presenting the principal crystalline planes found in its structure: $30.09^{\circ}(220), 3.42^{\circ}(311)$, $43.05^{\circ}(400), 53.39^{\circ}(422), 56.94^{\circ}(511)$, and $62.51^{\circ}(440)$. The reflection peaks represent the prominent crystalline peaks found in the magnetite structure. As for AC, a broad peak is observed due to $\mathrm{AC}$ amorphous structure (Fig. 2) and a slightly intense phase at approximately $20.7^{\circ}$, attributed to the graphitic carbon-based AC. This phase is no longer

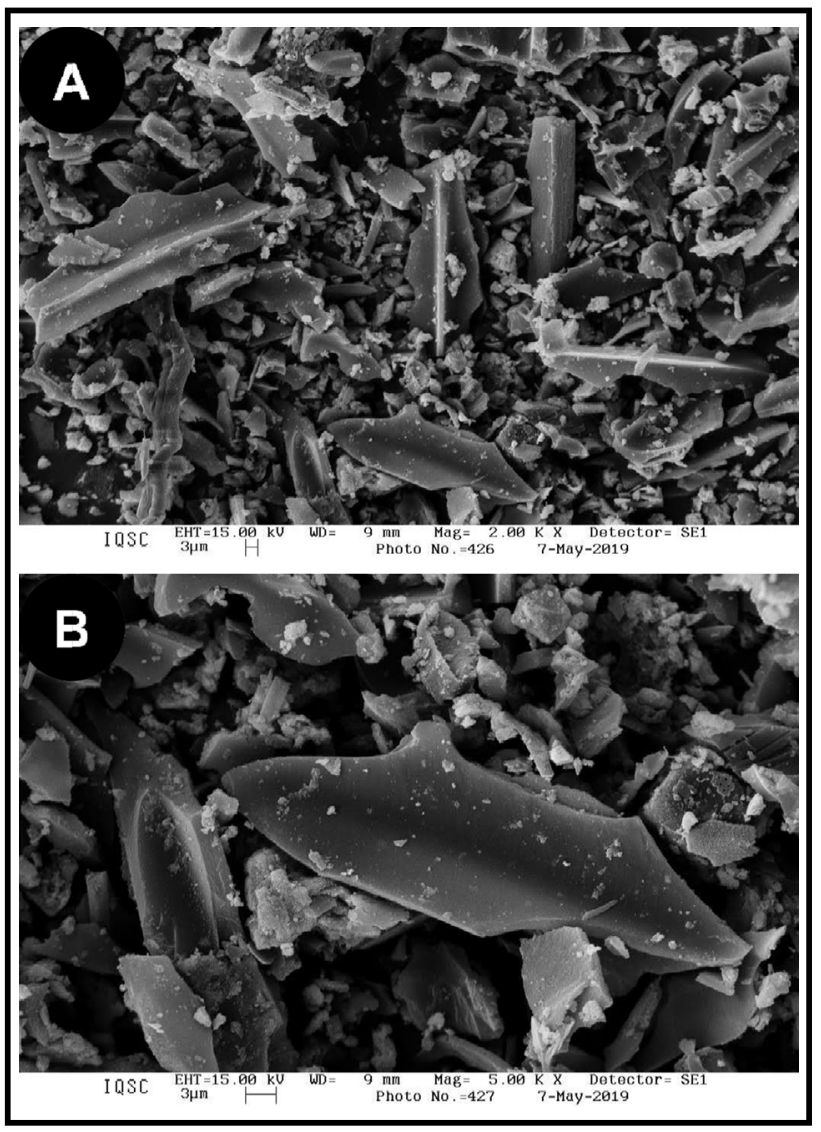

Fig. 1 Scanning electron microscopy (SEM) images of nanomodified activated carbon (AC-NP) obtained at A $2 \mathrm{~K} \times$ and $\mathbf{B} 5 \mathrm{~K} \times$ magnifications

observed after TMX adsorption by AC-NP. According to Namasivayam and Kavitha (2006), the adsorption reaction can change the molecular and crystalline structure of the adsorbent.

The identification of some functional groups in $\mathrm{AC}$ and AC-NP was performed by observing the prominent absorption bands in the spectra depicted in Fig. 3. AC bands at 3550 and $1603 \mathrm{~cm}^{-1}$ are characteristic of vibrational stretching of $\mathrm{O}-\mathrm{H}$ and $\mathrm{C}=\mathrm{C}$, respectively, and are specific groups in the AC structure. The FTIR of AC-NP shows the predominant bands of $\mathrm{AC}$ and from $\mathrm{Fe}-\mathrm{O}$ stretching of the magnetite at $610-570 \mathrm{~cm}^{-1}$, indicating that this material was efficiently synthesized and presented characteristics of its precursors (AC and NP).

FTIR spectra of AC-NP after TMX and TMX-I sorption in aqueous or sugarcane juice media were also acquired to assess whether characteristic TMX bands would be observed in the nanocomposite after sorption (Fig. 3).

It was observed that characteristic bands of TMX were present in AC-NP after sorption, such as the typical absorption band located between 1500 and $1600 \mathrm{~cm}^{-1}$ attributed to $\mathrm{NO}_{2}$ groups (Silva et al. 2021). The effect of the matrix 
Table 1 Reference values (standard plug JCPDF 88-0315) of $2 \theta$ for all peaks corresponding to $\mathrm{Fe}_{3} \mathrm{O}_{4}$, and the results for activated carbon (AC), magnetite nanoparticles (NP), and the nanocomposite prior
(AC-NP) and after (AC-NP+TMX) thiamethoxam sorption in aqueous medium; and the nanocomposite prior (AC-NP in juice) and after (AC-NP + TMX in juice) thiamethoxam sorption in sugarcane juice

\begin{tabular}{|c|c|c|c|c|c|c|c|c|}
\hline \multirow[t]{3}{*}{ Material } & \multicolumn{8}{|c|}{$2 \theta$ (degree) } \\
\hline & \multicolumn{8}{|l|}{ Peak } \\
\hline & 1 & 2 & 3 & 4 & 5 & 6 & 7 & 8 \\
\hline $\mathrm{AC}$ & 20.70 & 26.51 & 29.3 & 36.38 & & & & \\
\hline NP & 30.10 & & & 35.42 & 43.20 & 53.42 & 57.09 & 62.75 \\
\hline AC-NP & 20.78 & 26.49 & & 35.55 & 43.18 & 53.71 & 57.33 & 62.81 \\
\hline $\mathrm{AC}-\mathrm{NP}+\mathrm{TMX}$ & 26.36 & 30.14 & & 35.55 & 43.31 & 53.52 & 57.23 & 62.74 \\
\hline AC-NP + juice & 26.44 & 30.14 & & 35.53 & 43.24 & 53.65 & 57.32 & 62.83 \\
\hline $\mathrm{AC}-\mathrm{NP}+\mathrm{TMX}$ in juice & 26.45 & 30.11 & & 35.54 & 43.20 & 53.68 & 57.12 & 62.84 \\
\hline
\end{tabular}

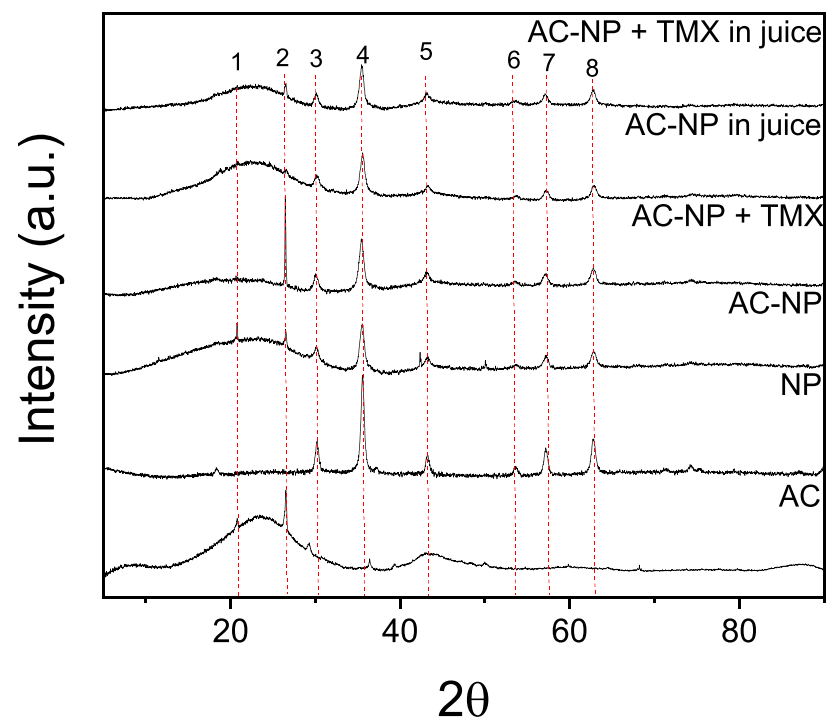

Fig. 2 X-ray diffractograms of activated carbon (AC), magnetite nanoparticles (NP), the nanocomposite prior (AC-NP) and after (AC$\mathrm{NP}+\mathrm{TMX})$ thiamethoxam sorption in aqueous medium; the nanocomposite prior (AC-NP in juice) and after (AC-NP+TMX in juice) thiamethoxam sorption in sugarcane juice. The 8 crystalize phases were identified by the JCPDS file number $88-031,524$. The graphic program used was the Origin 2020

(sugarcane juice) was not significant in the vibrational bands, indicating that this material can also be used in complex matrices with no substantial changes in its sorption sites.

The AC-NP magnetization strength is illustrated in Fig. 4. It exhibits images of the powdered AC-NP and its suspension in water and in sugarcane juice containing TMX, prior and after the imposition of a magnetic field using a neodymium magnet. The magnet electromagnetically attracts AC-NP, a phenomenon that occurs in approximately $60 \mathrm{~s}$. As previously discussed, this magnetic property resulting from AC-NP synthesis with $\mathrm{Fe}_{3} \mathrm{O}_{4}$ was also observed by the presence of the crystalline phases of the magnetite and verified by the characteristics stretches attributed to it in

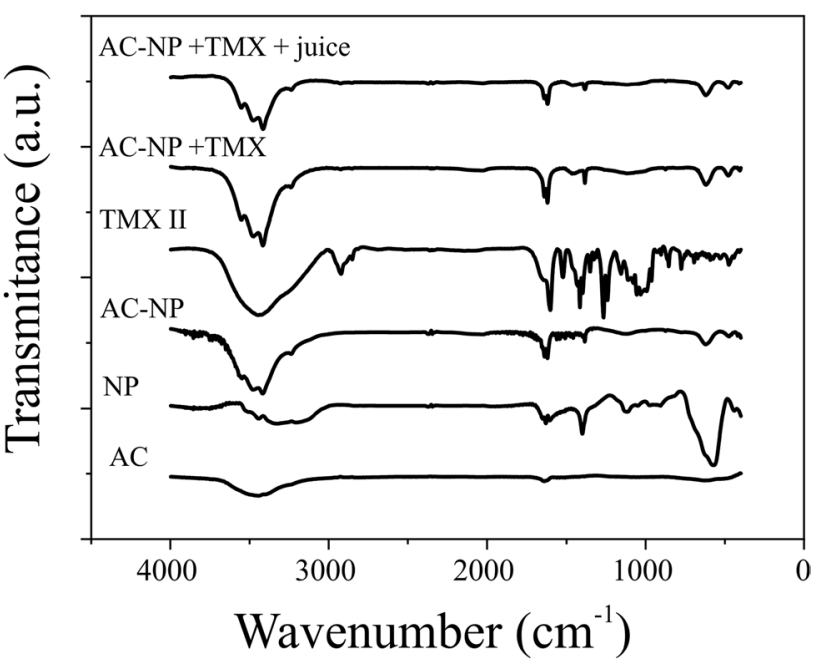

Fig. 3 FTIR spectra of the pesticide thiamethoxam (TMX), activated carbon (AC), magnetite nanoparticles (NP), the nanocomposite prior (AC-NP) and after TMX sorption in aqueous medium (AC$\mathrm{NP}+\mathrm{TMX})$ and in sugarcane juice (AC-NP+TMX+juice). The graphic program used was Origin 2020

the FTIR analysis. Also, it has been reported that magnetic activated carbon $\left(\mathrm{AC}-\mathrm{Fe}_{3} \mathrm{O}_{4}\right)$ exhibits magnetic saturation of $2.4158 \mathrm{emu} / \mathrm{g}$, and that its magnetic properties are provided by $\mathrm{Fe}_{3} \mathrm{O}_{4}$ and $\mathrm{Fe}$ (Zhang 2012).

It has been reported that pore volume of magnetic nanomodified AC slightly decreases compared with AC alone (Bastami and Entezari 2012; Gu et al. 2019; Kyzas et al. 2014; Veerakumar et al. 2016). According to these studies, activated carbon generated from different sources presented between 0 and $25 \%$ pore size reductions after $\mathrm{AC}$ modification with $\mathrm{Fe}_{3} \mathrm{O}_{4}$. They also demonstrated that the nanomodification of $\mathrm{AC}$ reduces the surface area to about 3 to $20 \%$. Linhares et al. (2016) reported that a commercial mesoporous AC (the same as used in our work) exhibited a surface area of $597 \mathrm{~m}^{2} / \mathrm{g}$ and a pore volume of $0.22 \mathrm{~cm}^{3} / \mathrm{g}$. Considering the results from these works, we believe it could 


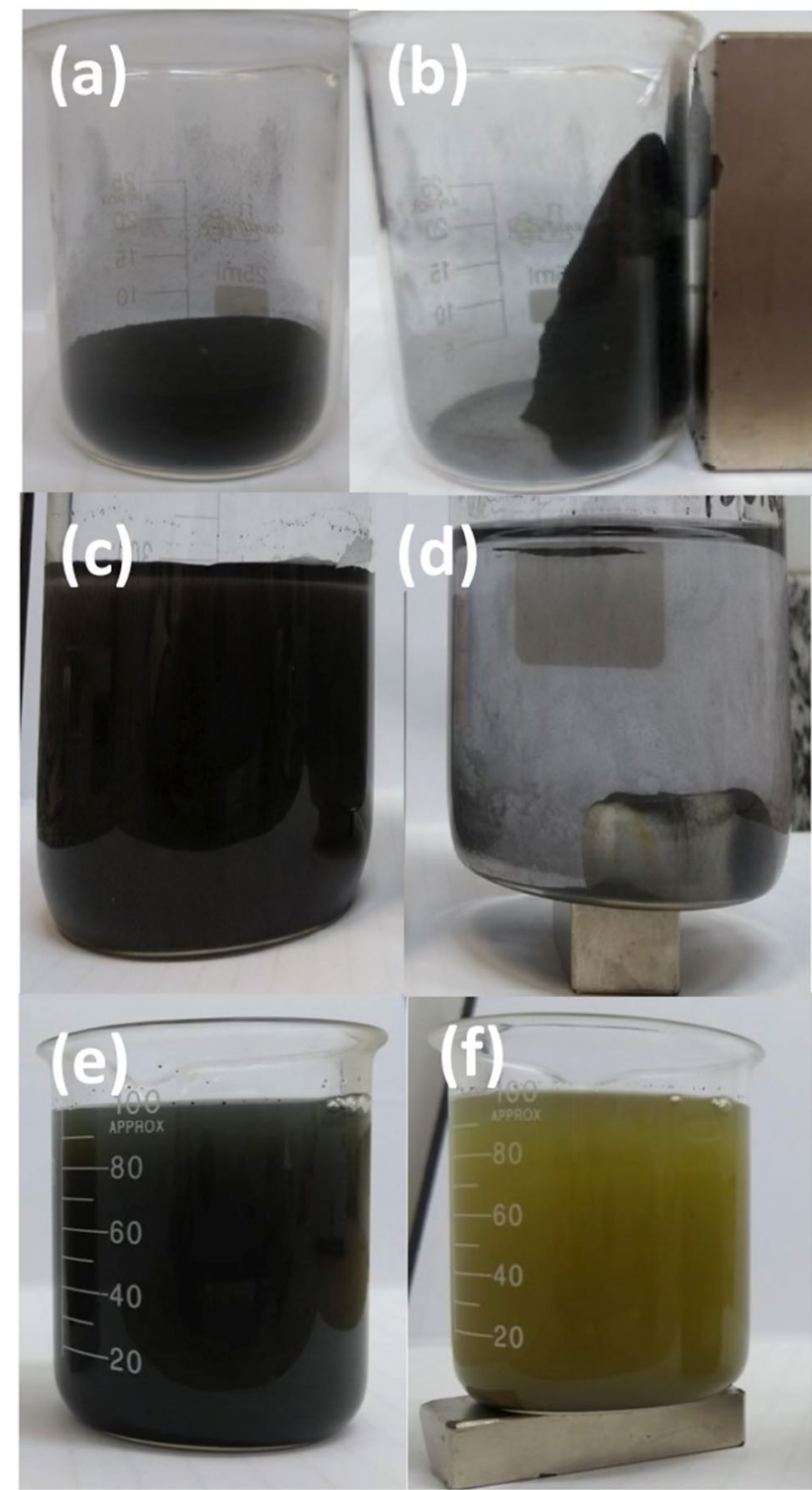

Fig. 4 Illustration of $\mathbf{a}$ the powdered AC-NP nanocomposite and its $\mathbf{b}$ magnetization effect; AC-NP-TMX suspension in $\mathbf{c}$ aqueous medium and $\mathbf{e}$ in sugarcane juice; and $\mathbf{d}$ and $\mathbf{f}$ after approximation of a neodymium magnet to these mixtures, respectively

be implied that AC-NP is expected to show slight changes in pore volume and surface area compared to AC.

In our previous works (Labuto et al. 2018; Debs et al. 2019; José et al. 2019; Barbosa et al. 2021; Carvalho et al. 2021; Abilio et al. 2021), we have demonstrated the potential of magnetic nanocomposites to remove contaminants in aqueous medium and the feasible separation of the supernatant from the adsorbent. To use AC-NP for pesticide removal in complex matrices, adsorption assays were performed in sugarcane juice. For this, the magnetic nanocomposite was

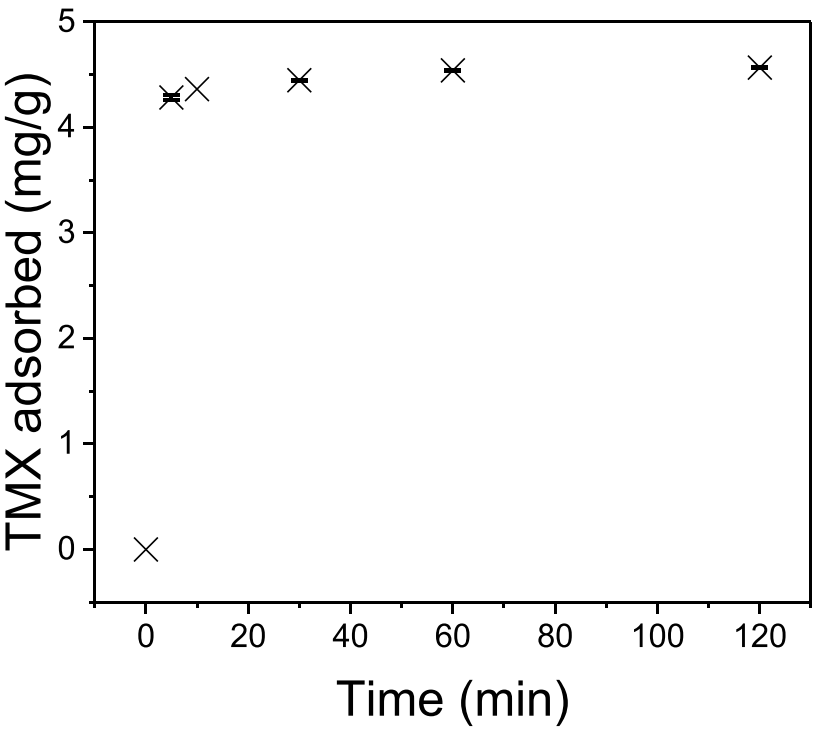

Fig. 5 Kinetics of thiamethoxam (TMX) adsorption by nanomodified activated carbon (AC-NP) using $10 \mathrm{mg} / \mathrm{L}$ TMX in sugarcane juice at pH 5.3. Mass of adsorbent $100 \mathrm{mg} . n=3$

evaluated by performing kinetic and isothermal models' adjustments.

\section{Kinetic studies}

The $\mathrm{pH}$ of natural and TMX-fortified $(10 \mathrm{mg} / \mathrm{L})$ sugarcane juice was 5.5 and 5.3, respectively, below the $\mathrm{AC}-\mathrm{NP} \mathrm{pH}_{\mathrm{PZC}}$. Therefore, no $\mathrm{pH}$ adjustment was necessary for TMX sorption by AC-NP in these samples. After the TMX adsorption process, the $\mathrm{pH}$ value of these solutions was 5.3.

Figure 5 exhibits the adsorption kinetics profile as a function of the contact time of TMX in sugarcane juice with the AC-NP nanocomposite. It is possible to verify that the sorption of this substance occurred quickly, in the first $10 \mathrm{~min}$, when almost $95 \%$ of TMX was adsorbed by AC-NP, indicating great sorption efficiency of this material.

Kinetic models of pseudo-first (Lagergren equation) and pseudo-second order (Ho 2006) were applied to the experimental data to determine the type of TMX adsorption. These models describe the sorption profile of substances by solids. Table 2 presents the parameters of the adjusted equations for TMX sorption and the parameters, in which $r^{2}$ represents the coefficient of determination and $k_{1}$ and $k_{2}$ are the first and second order constants, respectively, indicating the affinity between adsorbate and adsorbent. It can be concluded that both equations of pseudo-first and pseudo-second order provided suitable experimental adjustments due to the $r^{2}$ values. However, according to the $q_{\max }$ values of the models (Ho and Mckay 2000; Ho 2006), the pseudo-second order model describes the chemical adsorption process well, involving 
Table 2 Thiamethoxam (TMX) sorption kinetics data of pseudo-first and pseudo-second order using $100 \mathrm{mg}$ of nanomodified activated carbon (AC-NP) and $40 \mathrm{~mL}$ of $10 \mathrm{mg} / \mathrm{L}$ TMX solution, in sugarcane juice. $n=3$

\begin{tabular}{lllll}
\hline Kinetic model & \multicolumn{4}{l}{ TMX } \\
\cline { 2 - 5 } & $Q_{\max }(\mathrm{mg} / \mathrm{g})$ & $k_{1}$ or $k_{2}$ & $r^{2}$ & $\chi^{2}$ \\
\hline Pseudo-1st order & 0.343 & $0.041\left(\mathrm{~min}^{-1}\right)$ & 0.9780 & 0023 \\
Pseudo-2nd order & 4.59 & $0.375(\mathrm{~g} / \mathrm{mg} \cdot \mathrm{min})$ & 0.9999 & 0.003 \\
\hline
\end{tabular}

the exchange or donation of electrons between adsorbate and the adsorbent, as covalent and ion exchange forces.

\section{Experimental sorption capacity $\left(S C_{\text {exp }}\right)$ and isotherm assessment}

The $\mathrm{pH}$ of TMX aqueous solution and TMX-fortified (13.8, 19.1, 37.2, 58.7, 82.1, 98.5, 144.4, and 193.5 mg/L TMX) sugarcane juice was 5.5 , which is below the point of zero charge $\left(\mathrm{pH}_{\mathrm{PZC}}\right)$ of AC-NP (Barbosa et al. 2021). The final concentrations of TMX-I-fortified cane juice were 14.6, $35.9,72.2,122.2,301.4,730.7,1298.3$, and $2428.7 \mathrm{mg} / \mathrm{L}$ at $\mathrm{pH}$ 5.5. Therefore, there was no need to adjust the $\mathrm{pH}$ of these solutions. After sorption, all TMX and TMX-I solutions' $\mathrm{pH}$ value remained 5.3.

The adjustment of seven theoretical isothermal models (Langmuir, Freundlich, DR, Temkin, Hill, Sips, and RP) to the experimental data of TMX and TMX-I adsorption by AC-NP was applied. The results are depicted in Fig. 6, and their parameters are displayed in Table 3, providing information on the type of sorption that possibly occurred in each process. In Fig. 6, it is observed that the TMX sorption capacity $\left(S C_{\text {exp }}\right)$ by AC-NP was not reached, showing no adsorption plateau, denoting that the adsorbent was not saturated.

Table 3 presents $S C_{\text {exp }}$, the values of $r^{2}, \chi^{2}$, and the parameters provided by the adjusted isotherm models. It is possible to establish which models best describe the experimental data. $S C_{\text {exp }}$ for both TMX (standard) and TMX-I (insecticide) showed experimental values of 13.44 and $42.44 \mathrm{mg} / \mathrm{g}$, respectively. For studies conducted with TMX, it can be observed that all models presented acceptable values of $\chi^{2}$ for Hill, Sips, and RP (6 degrees of freedom, $\alpha=0.05$, which have a critical value of 1.635) and for Langmuir, Freundlich, Temkin ( 7 degrees of freedom, $\alpha=0.05$, which have a critical value of 2.167). For DR, the $\chi^{2}$ value was not acceptable for 7 degrees of freedom; this model was excluded to discussion. Searching for the models that presented values of $r^{2}$ closer to 1, we have as sequence of best fit Hill $>$ Freundlich $>$ RP $>$ Sips $>$ Langmuir $>$ Temkin. Hill isotherm describes a cooperative adsorption on a homogeneous substrate which was evidenced by the $n_{H}=27$ obtained, since $n>1$ denotes a positive cooperative binding (Al-Ghouti and Da'ana 2020). Considering the standard error (SE) values, Freundlich, Langmuir, and Sips models would be the most appropriate to describe the experimental data, in which the latter shows $r^{2}$ closer to 1 . It is in accordance with previous observations suggesting that these models are better suited to explaining pesticide, herbicide, and insecticide adsorption (Al-Ghouti and Da'ana 2020). Thus, Freundlich was considered the most suitable model for describing the TMX adsorption, suggesting a physical adsorption process (Milani et al. 2018a-b).

As for TMX-I (Fig. 6), it can be inferred by the adsorption plateau that maximum $S C_{\text {exp }}$ was reached, denoting the saturation of the adsorbent. Considering only the $r^{2}$ values obtained, it would be possible to describe a sequence of adjustment of the isotherm models to the

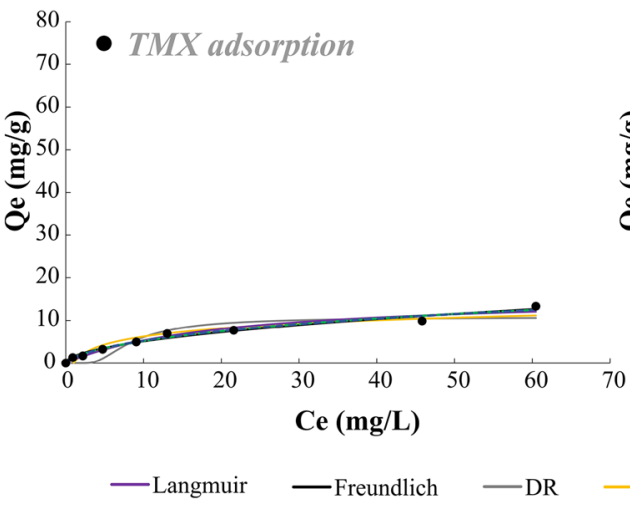

Fig. 6 Standard (TMX) and insecticide (TMX-I) thiamethoxam adsorption isotherms by nanomodified activated carbon (AC-NP) in sugarcane juice and the theoretical models of Langmuir, Freundlich, D-R, Temkin, Hill, SIPS, and RP adjusted to experimental data; $n=3$.

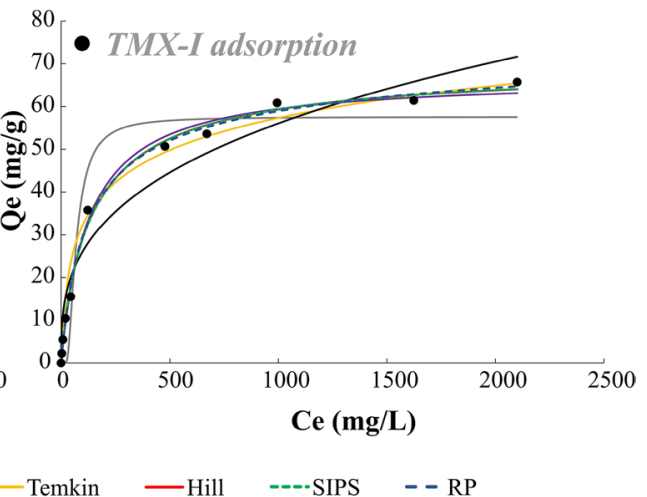

$C_{e}$, the concentration of adsorbed pesticide present in the solution after the sorption process, in equilibrium; $Q_{e}$, the concentration of adsorbed pesticide, in equilibrium 
Table 3 Langmuir, Freundlich, Dubinin-Radushkevich (D-R), Temkin, Hill, SIPS isotherms parameters, values of experimental sorption capacity $\left(S C_{\text {exp }}\right)$, and $\chi^{2}$ error evaluation for thiamethoxam (standard TMX and insecticide TMXI) sorption by nanomodified activated carbon (AC-NP)

\begin{tabular}{|c|c|c|c|}
\hline & & TMX & TMX-I \\
\hline \multicolumn{2}{|l|}{$S C_{\text {exp }}(\mathrm{mg} / \mathrm{g})$} & $13.44 \pm 0.02^{(\mathrm{SD})}$ & $42.44 \pm 1.25^{(\mathrm{SD})}$ \\
\hline Isotherm model & Parameters & & \\
\hline \multirow[t]{4}{*}{ Langmuir } & $q_{\max }(\mathrm{mg} / \mathrm{g})$ & $16.08 \pm 1.6^{(\mathrm{SE})}$ & $66.87 \pm 1.45^{(\mathrm{SE})}$ \\
\hline & $b(\mathrm{~L} / \mathrm{mg})$ & $0.05 \pm 0.012^{(\mathrm{SE})}$ & $0.0070 \pm 0.0008^{(\mathrm{SE})}$ \\
\hline & $r^{2}$ & 0.9673 & 0.9941 \\
\hline & $\chi^{2}$ & 0.63 & 4.12 \\
\hline \multirow[t]{4}{*}{ Freundlich } & $K_{f}(\mathrm{~L} / \mathrm{mg})$ & $1.57 \pm 0.25^{(\mathrm{SE})}$ & $5.71 \pm 1.62^{(\mathrm{SE})}$ \\
\hline & $n$ & $1.96 \pm 0.17^{(\mathrm{SE})}$ & $3.02 \pm 0.38^{(\mathrm{SE})}$ \\
\hline & $r^{2}$ & 0.9740 & 0.9483 \\
\hline & $\chi^{2}$ & 0.5 & 36.1 \\
\hline \multirow[t]{5}{*}{$D R$} & $q_{D R}(\mathrm{mg} / \mathrm{g})$ & $10.77 \pm 1.12^{(\mathrm{SE})}$ & $57.58 \pm 2.97^{(\mathrm{SE})}$ \\
\hline & $B_{D-R}\left(\mathrm{~mol}^{2} / \mathrm{J}^{2}\right)$ & $1.027 \times 10^{-5} \pm 4.00 \times 10^{-6(\mathrm{SE})}$ & $6.12 \times 10^{-4} \pm 2.14 \times 10^{-4(\mathrm{SE})}$ \\
\hline & $E(\mathrm{~kJ} / \mathrm{mol})$ & $486 \mathrm{~kJ} / \mathrm{mol}$ & $28.57 \mathrm{~kJ} / \mathrm{mol}$ \\
\hline & $r^{2}$ & 0.8457 & 0.9346 \\
\hline & $\chi^{2}$ & 2.97 & 45.72 \\
\hline \multirow[t]{4}{*}{ Temkin } & $A_{T}(\mathrm{~L} / \mathrm{g})$ & $34,239 \pm 3918^{(\mathrm{SE})}$ & $8629 \pm 470^{(\mathrm{SE})}$ \\
\hline & $b_{T}(\mathrm{~J} / \mathrm{mol})$ & $1.0 \pm 0.3^{(\mathrm{SE})}$ & $0.19 \pm 0.04^{(\mathrm{SE})}$ \\
\hline & $r^{2}$ & 0.9254 & 0.9762 \\
\hline & $\chi^{2}$ & 1.44 & 16.6 \\
\hline \multirow[t]{5}{*}{ Hill } & $Q_{S H}(\mathrm{mg} / \mathrm{L})$ & $40 \pm 59^{(\mathrm{SE})}$ & $70 \pm 3^{(\mathrm{SE})}$ \\
\hline & $K_{D}$ & $0.6 \pm 0.2^{(\mathrm{SE})}$ & $0.89 \pm 0.09^{(\mathrm{SE})}$ \\
\hline & $n_{H}$ & $27 \pm 34^{(\mathrm{SE})}$ & $82 \pm 28^{(\mathrm{SE})}$ \\
\hline & $r^{2}$ & 0.9989 & 0.9999 \\
\hline & $\chi^{2}$ & 0.52 & 3.87 \\
\hline \multirow[t]{5}{*}{ SIPS } & $q_{\max }(\mathrm{mg} / \mathrm{g})$ & $34.7 \pm 3.96^{(\mathrm{SE})}$ & $70.1 \pm 3.3^{(\mathrm{SE})}$ \\
\hline & $b(\mathrm{~L} / \mathrm{mg})$ & $0.0067 \pm 0.02^{(\mathrm{SE})}$ & $0.0068 \pm 0.0012^{(\mathrm{SE})}$ \\
\hline & $n$ & $0.64 \pm 0.21^{(\mathrm{SE})}$ & $0.887 \pm 0.085^{(\mathrm{SE})}$ \\
\hline & $r^{2}$ & 0.9716 & 0.9943 \\
\hline & $\chi^{2}$ & 0.55 & 3.95 \\
\hline \multirow[t]{5}{*}{$R P$} & $K_{R P}(\mathrm{~L} / \mathrm{g})$ & $2 \pm 2^{(\mathrm{SE})}$ & $0.63 \pm 0.09^{(\mathrm{SE})}$ \\
\hline & $a_{R P}(\mathrm{~L} / \mathrm{mg})$ & $1 \pm 1^{(\mathrm{SE})}$ & $0.015 \pm 0.006^{(\mathrm{SE})}$ \\
\hline & $g$ & $0.6 \pm 0.2^{(\mathrm{SE})}$ & $0.94 \pm 0.04^{(\mathrm{SE})}$ \\
\hline & $r^{2}$ & 0.9734 & 0.9950 \\
\hline & $\chi^{2}$ & 0.51 & 3.49 \\
\hline
\end{tabular}

$S D$, standard deviation; $S E$, standard error provided by fitting the model to the experimental data. $n=3$ experimental data as Hill $>$ RP $>$ Sips $\sim$ Langmuir $>$ Temkin $>$ Freundlich $>$ DR, with a $r^{2}=0.9999$ for Hill model. Based on this sequence and considering that the SE values of the parameters provided for all models were relatively low, we could suggest that the Hill isotherm model described the experimental data for TMX-I adsorption process, which would be in accordance with the findings observed for TMX. However, observing the $\chi^{2}$ for the Hill, Sips, and RP models ( 8 degrees of freedom of the experiment, $\alpha=0.05$, which have a critical value of 2.733) and for Langmuir, Freundlich, DR, and Temkin (9 degrees of freedom, $\alpha=0.05$, which have a critical value of 3.325), no model could be used to describe the experimental data; values indicated a considerable error in adjusting these models. This makes evident the importance of employing an error analysis in adsorption studies such as nonlinear chi-square test $\left(\chi^{2}\right)$ (Ayawei et al. 2017).

It is probably the effect of the complex matrix of sugarcane juice, which is composed of soluble ( $9.8 \%$ fermentable sugars) and insoluble substances from sugarcane bagasse ( $42 \%$ cellulose, $25 \%$ hemicellulose, and $20 \%$ lignin) (Kim and Day 2011). Soluble substances can affect the adsorption of TMX-I through interactions with the adsorbate or with the adsorption sites of the adsorbent, promoting the increase or decrease of the retained amounts. The insoluble components, even in much smaller amounts than the adsorbent, can also adsorb the TMX-I since they have sorption sites capable of removing organic and inorganic substances. 
The TMX-I is a commercial product that probably has other substances in its formulation that can either contribute or hinder the adsorption of TMX present in the insecticide by the studied adsorbent. It is important to consider that, although the isotherm studies did not provide acceptable adjustments for TMX-I, it was possible to remove $42.44 \pm 1.25$ (SD) $\mathrm{mg} / \mathrm{g}$ of adsorbate from the complex matrix of sugarcane juice. This is about 4 times more than the amount of standard TMX removed from the same matrix. This suggests some kind of positive synergy in the TMX-I adsorptive process, probably due to some unknown component present in the insecticide.

\section{Conclusions}

Sugarcane is one of the most important agricultural cultivars in the Brazilian economy. Due to its broad applicability in artisanal and industrial processes and the use of thiamethoxam (TMX) in its cultivation, quantifying this pesticide in sugarcane juice was highly relevant. Therefore, we have proposed the removal of the pesticide most used for sugarcane cultivation from the juice used for the production of sugar.

The magnetic activated carbon nanocomposite (AC-NP) efficiently removed TMX from sugarcane juice, an extremely complex matrix, and from water. The magnetization of AC was a strategy to facilitate the separation of the adsorbent from the liquid matrix from which the contaminant was removed. The structural characterization of AC-NP and the $\mathrm{AC}$ nanomodification with $\mathrm{Fe}_{3} \mathrm{O}_{4}$ was estimated by the crystalline peaks presented in the XRD diffractogram and the $\mathrm{Fe}-\mathrm{O}$ vibrational stretching from $\mathrm{Fe}_{3} \mathrm{O}_{4}$ observed in the FTIR analysis.

The adsorption kinetics of TMX in sugarcane juice was best adjusted to the pseudo-second-order type, indicating that a chemical process occurred in the sorption of TMX. Significant values of experimental sorption capacity $\left(S C_{\text {exp }}\right)$ by AC-NP to remove TMX and TMX-I from sugarcane juice were 13.44 and $42.44 \mathrm{mg} / \mathrm{g}$, respectively. And the best fit for the isothermal models considering only the high $r^{2}$ values was found to be Hill for both TMX and TMX-I. The chromatographic method for quantifying TMX and TMX-I in both aqueous and sugarcane juice matrices was selective and highly satisfactory for their quantification. The efficiency of AC-NP in the sorption of TMX was confirmed by the excellent values of $S C_{\text {exp }}$ and favorable sorption kinetics, indicating its fair use in removing pesticides from complex matrices.

Author contribution EC, GL, and RFN postulated and supervised the study. DAF and EC planned the experiment. DAF obtained the data, and $\mathrm{EC}, \mathrm{GL}$, and JAB carried out the data analysis and interpretation.
GL performed the adjustment of all experimental data to the isothermal models applied. DAF and JAB prepared the first draft, and EC and GL thoroughly revised the manuscript. EC, GL, and DAF read and approved the final manuscript.

Funding This work was supported by Fundação de Amparo à Pesquisa do Estado de São Paulo (FAPESP, Grant 2016/06271-4). The authors are grateful to Coordenação de Aperfeiçoamento de Pessoal de Nível Superior (CAPES) and Conselho Nacional de Desenvolvimento Científico e Tecnológico (CNPq) for the scholarships provided.

Data availability All data generated or analyzed during this study are included in this published article. Extra data are available from the authors (elma.carrilho@gmail.com) upon reasonable request.

\section{Declarations}

Ethics approval Not applicable.

Consent to participate Not applicable.

Consent for publication Not applicable.

Competing interests The authors declare no competing interests.

\section{References}

Abilio TA, Soares BC, José JC, Milani PA, Labuto G, Carrilho ENVM (2021) Hexavalent chromium removal from water: adsorption properties of in natura and magnetic nanomodified sugarcane bagasse. Environmental Science and Pollution Research 28(19):24816-24829. https://doi.org/10.1007/ s11356-020-11726-8

Al-Ghouti MA, Da'ana DA (2020) Guidelines for the use and interpretation of adsorption isotherm models: a review. J Hazard Mat 393(5):122383. https://doi.org/10.1016/j.jhazmat.2020.122383

Angelo C (2012) Growth of ethanol fuel stalls in Brazil. Nature News 491(7426):646

Antunes-Kenyon SE, Kennedy G (2001) Thiamethoxam: a new active ingredient review. Massachusetts: Massachusetts Pesticide Bureau

Ayawei N, Ebelegi AN, Wankasi D (2017) Modelling and interpretation of adsorption isotherms. J Chem. https://doi.org/10.1155/ 2017/3039817

Barbosa JA, Labuto G, Carrilho ENVM (2021) Magnetic nanomodified activated carbon: characterization and use for organic acids sorption in aqueous medium. Chem Eng Commun 208(10):1450 1463. https://doi.org/10.1080/00986445.2020.1791832

Bastami TR, Entezari MH (2012) Activated carbon from carrot dross combined with magnetite nanoparticles for the efficient removal of p-nitrophenol from aqueous solution. Chem Eng J 210:510-519. https://doi.org/10.1016/J.CEJ.2012.08.011

Brandt A, Gorenflo A, Siede R, Meixner M, Büchler R (2016) The neonicotinoids thiacloprid, imidacloprid, and clothianidin affect the immunocompetence of honey bees (Apis mellifera L.). J Insect Physiol 86:40-47. https://doi.org/10.1016/j.jinsphys.2016.01.001

Cardona DS, Debs KB, Lemos SG, Vitale G, Nassar NN, Carrilho ENVM, Semensatto D, Labuto G (2019) A comparison study of cleanup techniques for oil spill treatment using magnetic nanomaterials. Journal of Environmental Management 242:362-371. https://doi.org/10.1016/j.jenvman.2019.04.106 
Carrilho ENVM, Labuto G, Kamogawa MY (2016) Destination of vinasse, a residue from alcohol industry: resource recovery and prevention of pollution. In Environmental materials and waste (pp. 21-43) Academic Press

Carvalho JTT, Milani AP, Consonni JL, Labuto G, Carrilho ENVM (2021) Nanomodified sugarcane bagasse biosorbent: synthesis, characterization, and application for $\mathrm{Cu}(\mathrm{II})$ removal from aqueous medium. Environ Sci Pollut Res 28:24744-24755. https://link. springer.com/article/10.1007/s11356-020-11345-3

CONAB (Companhia Nacional de Abastecimento) (2021) Cana-deaçúcar, safra 2020/21, $3^{\circ}$ levantamento. Available in: <https:// www.conab.gov.br/info-agro/safras/cana/boletim-da-safra-decana-de-acucar $>$ Accessed 07 March 2021

Debs KB, Cardona DS, Silva HDT, Nassar N, Carrilho ENVM, Haddad PS, Labuto G (2019) Oil spill cleanup employing magnetite nanoparticles and yeast-based magnetic bionanocomposite. J Environ Manag 230:405-412

Gu SY, Hsieh CT, Gandomi YA, Yang ZF, Li L, Fu CC, Juang RS (2019) Functionalization of activated carbons with magnetic Iron oxide nanoparticles for removal of copper ions from aqueous solution. J Molec Liq 277:499-505

EFSA - European Food Safety Authority (2014). Reasoned opinion on the review of the existing maximum residue levels (MRLs) for clothianidin and thiamethoxam according to Article 12 of Regulation (EC) No 396/2005. EFSA Journal 12(12):3918, 120 pp. https://doi.org/10.2903/j.efsa.2014.3918

El-Sheikh AH, Sweileh J, Al-Degs YS, Insisi AA, Al-Rabady N (2007) Critical evaluation and comparison of enrichment efficiency of multi-walled carbon nanotubes, C18 silica and activated carbon towards some pesticides from environmental waters. Talanta 74:1675-1680. https://doi.org/10.1016/j.talanta.2007.09.005

EPA - Environmental Protection Agency (2020) Clothianidin and thiamethoxam proposed interim registration review decision case numbers 7620 and 7614, docket numbers EPA-HQOPP-2011-0865 and EPA-HQ-OPP-2011-0581. Available in: https://www.epa.gov/sites/default/files/2020-01/documents/cloth ianidin_and_thiamethoxam_pid_final_1.pdf

Foo KY, Hameed BH (2010) Detoxification of pesticide waste via activated carbon adsorption process. J Hazard Mater 175(1-3):1-11. https://doi.org/10.1016/j.jhazmat.2009.10.014

Gupta VK, Gupta B, Rastogi A, Agarwal S, Nayak A (2011) Pesticides removal from waste water by activated carbon prepared from waste rubber tire. Water Res 45(13):4047-4055. https://doi.org/ 10.1016/j.watres.2011.05.016

Ho YS (2006) Review of second-order models for adsorption systems. J Hazard Mater 136:681-689. https://doi.org/10.1016/j.jhazmat. 2005.12.043

Ho YS, Mckay G (2000) The kinetics of sorption of divalent metal ions onto sphagnum moss peat. Water Res 34:735-742. https://doi.org/ 10.1016/S0043-1354(99)00232-8

Jiménez-López J, Llorent-Martínez EJ, Ortega-Barrales P, RuizMedina A (2020) Analysis of neonicotinoid pesticides in the agri-food sector: a critical assessment of the state of the art. App Spectros Rev 55(8):613-646. https://doi.org/10.1080/05704928. 2019.1608111

José JC, Debs KB, Labuto G, Carrilho ENVM (2019) Synthesis, characterization, and application of yeast-based magnetic bionanocomposite for the removal of $\mathrm{Cu}$ (II) from water. Chem Engineering Communications. 1-11. https://doi.org/10.1080/00986 445.2019.1615468

Kim M, Day DF (2011) Composition of sugar cane, energy cane, and sweet sorghum suitable for ethanol production at Louisiana sugar mills. J Ind Microbiol Biotechnol 38(7):803-807. https://doi.org/ 10.1007/s10295-010-0812-8
Kyzas GZ, Deliyanni EA, Lazaridis NK (2014) Magnetic modification of microporous carbon for dye adsorption. J Colloid Interf Sci 430:166-173

Labuto G, Cardona DS, Debs KB, Imamura AR, Bezerra KCH, Carrilho ENVM, Haddad PS (2018) Low cost agroindustrial biomasses and ferromagnetic bionanocomposites to cleanup textile effluents. Desalin Water Treat 12:80-89. https://doi.org/10.5004/ dwt.2018.21914

Linhares FA, Marcílio NR, Melo PJ (2016) Estudo da produção de carvão ativado a partir do resíduo de casca da acácia negra com e sem ativação química. Scientia cum Industria 4(2):74-79. https:// doi.org/10.18226/23185279.v4iss2p74

Maienfisch P, Angst M, Brandl F, Fischer W, Hofer D, Kayser H, Widmer H (2001) Chemistry and biology of thiamethoxam: a secondgeneration neonicotinoid. Pes Manag Sci Sussex 57(10):906-913. https://doi.org/10.1002/ps.365

Milani PA, Debs KB, Labuto G, Carrilho ENVM (2018a) Agricultural solid waste for sorption of metal ions: part I-characterization and use of lettuce roots and sugarcane bagasse for $\mathrm{Cu}(\mathrm{II})$, $\mathrm{Fe}(\mathrm{II}), \mathrm{Zn}(\mathrm{II})$, and $\mathrm{Mn}(\mathrm{II})$ sorption from aqueous medium. Environ Sci Pollut Res 25:35895-35905. https://doi.org/10.1007/ s11356-018-1615-0

Milani PA, Debs KB, Labuto G, Carrilho ENVM (2018b) Agricultural solid waste for sorption of metal ions, part II: competitive assessment in multielemental solution and lake water. Environ Sci Pollut Res 25:35906-35914. https://doi.org/10.1007/s11356-018-1726-7

Modesto HR, Lemos SG, Santos MS, Komatsu JS, Gonçalves M, Carvalho WA, Carrilho ENVM, Labuto G (2021) Activated carbon production from industrial yeast residue to boost up circular bioeconomy. Environ Sci Pollut Res 28:24694-24705. https://doi.org/ 10.1007/s11356-020-10458-z

Namasivayam C, Kavitha D (2006) IR, XRD and SEM studies on the mechanism of adsorption of dyes and phenols by coir pith carbon from aqueous phase. Microchem J 82(1):43-48. https://doi.org/ 10.1016/j.microc.2005.07.002

Panneerselvam P, Morad N, Tan KA (2011) Magnetic nanoparticle $\left(\mathrm{Fe}_{3} \mathrm{O}_{4}\right)$ impregnated onto tea waste for the removal of nickel (II) from aqueous solution. J Hazard Materer 186:160-168. https:// doi.org/10.1016/j.jhazmat.2010.10.102

Pyrzynska K (2013) Use of nanomaterials in sample preparation. TrAC 43:100-108. https://doi.org/10.1016/j.trac.2012.09.022

Ravaneli GC, Madaleno LL, Presotti LE, Mutton MA, Mutton MJR (2006) Spittlebug infestation in sugarcane affects ethanolic fermentation. Scientia Agricola 63(6):534-539

Rodrigues SA, Caldas SS, Primel EG (2010) A simple efficient and environmentally friendly method for the extraction of pesticides from onion by matrix solid-phase dispersion with liquid chromatography-tandem mass spectrometric detection. Anal Chim Acta 678(1):82-89. https://doi.org/10.1016/j.aca.2010.08.026

Silva CF, Menezes LF, Pereira AC, Nascimento CS Jr (2021) Molecularly imprinted polymer (MIP) for thiamethoxam: a theoretical and experimental study. J Molec Struc 1231:129980. https://doi. org/10.1016/j.molstruc.2021.129980

Suganthi A, Bhuvaneswari K, Ramya M (2018) Determination of neonicotinoid insecticide residues in sugarcane juice using LCMSMS. Food Chem 241:275-280. https://doi.org/10.1016/j.foodchem. 2017.08.098

Uğurlu P, Ünlü E, Satar EI (2015) The toxicological effects of thiamethoxam on Gammarus kischineffensis (Schellenberg 1937) (Crustacea: Amphipoda). Environ Toxicol Pharm 39(2):720-726. https://doi.org/10.1016/j.etap.2015.01.013

USDA (United States Departament of Agriculture) (2020) Brazilian commodity prices hit record levels. Available in: https://www.fas. usda.gov/data/brazil-brazilian-commodity-prices-hit-record-levels Accessed 10 March 2021 
Veerakumar P, Panneer Muthuselvam I, Hung CT, Lin KC, Chou FC, Liu SB (2016) Biomass-derived activated carbon supported $\mathrm{Fe}_{3} \mathrm{O}_{4}$ nanoparticles as recyclable catalysts for reduction of nitroarenes. ACS Sustain Chem Eng 4:6772-6782

Wen Y (2020) Recent advances in solid-phase extraction techniques with nanomaterials. In: Hussain Chaudhery Mustansar (ed) Handbook of nanomaterials in analytical chemistry: modern trends in analysis. Elsevier, Cambridge, pp 57-73. https://doi.org/10.1016/ B978-12-816699-4.00004-9

Zhang J (2012) Preparation and characterization of magnetic coalbased activated carbon in the presence of $\mathrm{Fe}_{3} \mathrm{O}_{4}$. Advanc Mat
Res 393-395:1355-1358. https://doi.org/10.4028/www.scientific. net/AMR.393-395.1355

Publisher's note Springer Nature remains neutral with regard to jurisdictional claims in published maps and institutional affiliations. 